\title{
Development of a Breast Cancer Awareness Scale for Thai Women: Moving towards a Validated Measure
}

\author{
Nitchamon Rakkapao ${ }^{1}$, Supannee Promthet ${ }^{2,3}$, Malcolm A Moore ${ }^{2,3}$, Cameron P \\ Hurst $^{2,4 *}$
}

\begin{abstract}
Background: Breast cancer is a major health problem among women around the world. Recent developments in screening and treatment have greatly improved the prognosis of patients with breast cancer in developed countries. However, in developing countries breast cancer mortality remains high.Breast cancer awareness is a first and important step in reducing breast cancer mortality. The development of a validated instrument to measure breast cancer awareness is crucial for the understanding and implementation of suitable health education programs to facilitate early deletion and minimize mortality. Objective: The objective of this study was to develop an instrument for the assessment of breast cancer awareness in Thai women. Materials and Methods: This methodological study was conducted in two stages: (1) literature searches and semi-structured interviews were conducted to generate items of the breast cancer awareness scale (B-CAS) which were subsequently examined for content and face validity, and (2) an exploration of the factor structure of the resulting instrument and an examination of its reliability. Data were collected using a self-administered questionnaire in Thai women aged 20-64 in August, 2015. Results: A total of 219 women (response rate $97.4 \%$ ) participated in this validation study. The B-CAS contains five domains with 53 items on breast cancer awareness: 1) knowledge of risk factors, 2) knowledge of signs and symptoms, 3) attitude to breast cancer prevention, 4) barriers of breast screening, and 5) health behavior related to breast cancer awareness. Items with a content validity index $<0.80$ were excluded, and factor structure for the remaining items reflected the hypothesized five factor model. The scales based on all retained items was shown to have strongly internal consistency reliability (Cronbach's $\alpha=0.86)$. Conclusions: The B-CAS provides good psychometric properties to assess breast cancer awareness in women. It can be used to examine breast cancer awareness in Thai women and it could lead to the development and evaluation of suitable educational interventions for raising breast cancer awareness. Future research should focus on further validating the B-CAS including an assessment of construct and criterion-based validity.
\end{abstract}

Keywords: Breast cancer - breast cancer awareness - instrument development - Thai women

Asian Pac J Cancer Prev, 17 (2), 851-856

\section{Introduction}

Breast cancer is the most prevalent cancer in women throughout the world and one of the leading causes of cancer-related deaths in both developed and developing countries. (Ferlay et al., 2012). In Asian countries, breast cancer is the most diagnosed female cancer and increasing incidence has been observed in several Asian countries (Long et al., 2010; Moore et al., 2010; Moore et al., 2010; Moore et al., 2010; Youlden et al., 2014). This has led to several studies investigating the actual problem by way of studying breast cancer awareness (Khokhar, 2009; Al-Dubai et al., 2011; Kanaga et al., 2011; Gurdal et al., 2012; Wu et al., 2012; Yoo et al., 2012; Donnelly et al., 2013; Norlaili et al., 2013; Radi, 2013; Liu et al., 2014; Sathian et al., 2014; Miyawaki, Shibata et al., 2014; Tazhibi and Feizi, 2014). Most studies have found that the awareness of breast cancer in developing countries was weak compared with developed countries (Jones et al., 2010; Kwok et al., 2012).

In Thailand, breast cancer has been the most common cancer among women for the last 10 years and the age-standardized incidence rate has been continuously increasing (Khuhaprema et al., 2010; Khuhaprema et al., 2012; Khuhaprema et al., 2013). In addition, many Thai women with breast cancer are often only diagnosed at the advance stages of the disease (National Cancer Institute of Thailand, 2010; 2011; 2012). One of the main causes of the delayed diagnosis in developing countries is poor breast cancer awareness and barriers to health care service access. (Akinyemiju, 2012; Tripathi et al., 2014; Unger, 2014; Youlden et al., 2014). Breast cancer awareness has been widely accepted as the first step in the battle against breast cancer. Consequently, there is 
a need for urgent strategies in improving great cancer awareness in Thai women. The development of standard instruments to assess breast cancer awareness is crucial to design and implement suitable intervention for breast cancer prevention.

Previous studies attempting to measure breast cancer awareness often contain design and/or methodological limitations. Some studies conducted pilot testing and their validation process only involved content validity; they do not go on to fully validate their instruments (Norlaili et al., 2013; Ranasinghe et al., 2013; Liu et al., 2014a; Sathian et al., 2014). One study, conducted by Cancer Research UK, King's College London and University College London, developed and did attempt to fully validate their instrument, the Breast CAM. However, the design of their instrument led to limitations on how well it could be validated. For instance, one domain only contained a single item and another Breast CAM domain asked participants to circle signs and symptoms (All of which were signs and symptoms of breast cancer). Such an approach does not lend itself to the quantification of the constructs underlying breast cancer awareness. In addition, Breast CAM was developed in the west where etiologic factors and health policy of breast cancer differ considerably from the Asian context. There is a need to develop and validate an instrument to assess breast cancer awareness for the Thai-speaking population, and one that adheres to good practice in terms of the development of psychometric instruments. Understanding Thai women's breast cancer awareness will help healthcare professionals and policy makers to design and implement health education programs with the potential to increase awareness of breast cancer. The objective of this study was to develop and perform early-stage validation of an instrument to assess breast cancer awareness in Thai women.

\section{Materials and Methods}

Sample and data collection
Table 2. Demographic characteristics of participants in the Exploratory Factor Analysis (EFA)

\begin{tabular}{|c|c|c|}
\hline Characteristics & $\mathrm{n}=219$ & $\%$ \\
\hline \multicolumn{3}{|l|}{ Age group } \\
\hline Early adulthood (20-34 y) & 87 & 39.7 \\
\hline Adulthood (35-59 y) & 118 & 53.9 \\
\hline Elderly (60-64 y) & 14 & 6.4 \\
\hline \multicolumn{3}{|l|}{ Education level } \\
\hline Primary school & 89 & 40.6 \\
\hline High School & 57 & 26.0 \\
\hline Diploma or equal & 12 & 5.5 \\
\hline Bachelor degree & 51 & 23.3 \\
\hline Higher than Bachelor degree & 10 & 4.6 \\
\hline \multicolumn{3}{|l|}{ Occupation } \\
\hline Agriculture & 112 & 51.1 \\
\hline Trader & 34 & 15.5 \\
\hline Laborer & 12 & 5.5 \\
\hline Government official/enterprise/business & 40 & 18.3 \\
\hline Out of work & 7 & 3.2 \\
\hline Other & 14 & 6.4 \\
\hline \multicolumn{3}{|l|}{ Religion } \\
\hline Buddhism & 212 & 96.8 \\
\hline Muslim & 6 & 2.7 \\
\hline Christian & 1 & 0.5 \\
\hline \multicolumn{3}{|l|}{ Marital status } \\
\hline Single & 41 & 18.7 \\
\hline Married/Partner & 167 & 76.3 \\
\hline Widowed/Divorced/Separated & 11 & 5.0 \\
\hline \multicolumn{3}{|l|}{ Family income } \\
\hline Enough and with savings & 102 & 46.6 \\
\hline Enough but no savings & 106 & 48.4 \\
\hline Not enough and no debt & 5 & 2.3 \\
\hline Not enough and in debt & 6 & 2.7 \\
\hline \multicolumn{3}{|l|}{ Family history of cancer } \\
\hline Yes & 83 & 37.9 \\
\hline No & 136 & 62.1 \\
\hline \multicolumn{3}{|l|}{ Family history of breast cancer } \\
\hline Yes & 10 & 4.6 \\
\hline No & 209 & 95.4 \\
\hline \multicolumn{3}{|l|}{ Locality } \\
\hline Rural & 154 & 70.3 \\
\hline Urban & 65 & 29.7 \\
\hline
\end{tabular}

Table 1. Summary of Content and Scoring of the B-CAS

\begin{tabular}{|c|c|c|c|}
\hline Domains & Domains description & No. of Item & Scoring \\
\hline $\begin{array}{c}\text { Knowledge of risk factors of breast } \\
\text { cancer }\end{array}$ & $\begin{array}{l}\text { Modifiable risk factors (diet, } \\
\text { exercise and lifestyle) and non- } \\
\text { modifiable risk factors (genetic, } \\
\text { aging and hormone) }\end{array}$ & $\begin{array}{c}14 \\
\text { (2 trick questions) }\end{array}$ & $\begin{array}{l}2=\text { correct answer } \\
1=\text { don't know answer } \\
0=\text { incorrect answer }\end{array}$ \\
\hline $\begin{array}{c}\text { Knowledge of signs and symptoms } \\
\text { of breast cancer }\end{array}$ & $\begin{array}{c}\text { Breast cancer symptoms and non- } \\
\text { symptoms }\end{array}$ & $\begin{array}{c}10 \\
(2 \text { trick questions })\end{array}$ & $\begin{array}{l}2=\text { correct answer } \\
1=\text { don't know answer } \\
0=\text { incorrect answer }\end{array}$ \\
\hline Attitude to breast cancer prevention & $\begin{array}{c}\text { Breast screening and healthy } \\
\text { behavior }\end{array}$ & 8 & $\begin{array}{l}\text { rated on a 5-point Likert scale; } \\
\text { strongly agree to strongly disa- } \\
\text { gree, scoring from } 5 \text { to } 1\end{array}$ \\
\hline Barriers of breast screening & $\begin{array}{c}\text { Emotional, service delivery and } \\
\text { practical barriers }\end{array}$ & 9 & $\begin{array}{l}\text { rated on a 5-point Likert scale; } \\
\text { strongly agree to strongly disa- } \\
\text { gree, scoring from } 5 \text { to } 1\end{array}$ \\
\hline $\begin{array}{l}\text { Health behavior related to breast } \\
\text { cancer awareness }\end{array}$ & $\begin{array}{c}\text { Breast screening, healthy behavior } \\
\text { relation to food consumption and } \\
\text { exercise }\end{array}$ & 12 & $\begin{array}{l}\text { Frequency scale were rated on } \\
5 \text { scales; scoring from } 5 \text { to } 1\end{array}$ \\
\hline
\end{tabular}

* The scoring was reversed for negative statement 
Our study was conducted in women aged 20 to 64 years in southern Thailand in August, 2015. Sample size calculation was based on the assessment of factor analysis to establish construct validity (Comrey and Lee, 1992). Communities from a rural and urban area of Suratthani province, Thailand were chosen and stratified random sampling was used to select participants. Permission to collect the data was obtained from the head of each community.
A sample of 219 Thai women were recruited from both areas based on two criteria (locality and age groups) using convenience sampling. All participants were informed by the researchers and provided informed consent before data collection. Women who were diagnosed with breast cancer, pregnancy or breast feeding, or were illiterate in the Thai language were excluded from our study.The study's protocol was approved by the ethics committees of Khon Kaen University (HE 582053).

\section{Table 3. Pattern matrixcoefficient andcommunities (h2) from Principal Axis Factoring}

\begin{tabular}{|c|c|c|c|c|c|c|}
\hline \multirow{2}{*}{ Domains } & \multicolumn{5}{|c|}{ Factors loading } & \multirow[t]{2}{*}{$\mathrm{h} 2$} \\
\hline & 1 & 2 & 3 & 4 & 5 & \\
\hline \multicolumn{7}{|l|}{ Knowledge of risk factors (9) } \\
\hline Family history & & & $0.12 *$ & & & 0.11 \\
\hline Using a contraceptive drug & & & 0.58 & & & 0.4 \\
\hline Using hormone replacement therapy & & & 0.64 & & & 0.44 \\
\hline Starting your period before 12 years of age & & & 0.59 & & & 0.42 \\
\hline Late menopause after 55 years of age & & & 0.74 & & & 0.53 \\
\hline Null parity/infertility & & & 0.52 & & & 0.35 \\
\hline Having your first child after the age of 30 & & & 0.43 & & & 0.23 \\
\hline Eating diet high in fat & & & 0.32 & & & 0.13 \\
\hline Being overweight & & & 0.32 & & & 0.12 \\
\hline \multicolumn{7}{|l|}{ Knowledge of warning signs (8) } \\
\hline Discharge or bleeding from your nipple & $0.15^{*}$ & & & & & 0.15 \\
\hline Swelling of all or part of a breast or armpit & 0.38 & & & & & 0.41 \\
\hline Changes in the shape, size and colour of your breast and nipple & 0.75 & & & & & 0.61 \\
\hline Pain in one of your breasts or armpit & 0.72 & & & & & 0.53 \\
\hline Pulling in of your nipple & 0.7 & & & & & 0.56 \\
\hline A lump or thickening under your armpit & 0.46 & & & & & 0.31 \\
\hline Puckering or dimpling of your breast skin & 0.78 & & & & & 0.6 \\
\hline A lump or thickening in your breast & $0.17 *$ & & & & & 0.2 \\
\hline \multicolumn{7}{|l|}{ Attitude to breast cancer prevention(6) } \\
\hline $\begin{array}{l}\text { I think that breast cancer can be prevented by decreasing risk factors of breast } \\
\text { cancer. }\end{array}$ & & 0.42 & & & & 0.24 \\
\hline I think that breast cancer is curable if I can detect it at early stage. & & 0.59 & & & & 0.45 \\
\hline $\begin{array}{l}\text { I think that performing frequent examinations with health personnel can detect } \\
\text { breast cancer at an early stage }\end{array}$ & & 0.71 & & & & 0.56 \\
\hline $\begin{array}{l}\text { I think that performing mammography frequently can detect breast cancer at an } \\
\text { early stage. }\end{array}$ & & 0.8 & & & & 0.65 \\
\hline I think that exercise can decrease breast cancer risk. & & 0.87 & & & & 0.76 \\
\hline I think that decreasing a high fat diet can decrease breast cancer risk. & & 0.82 & & & & 0.69 \\
\hline \multicolumn{7}{|l|}{ Barrier of breast screening (4) } \\
\hline It is not convenient for me to see a doctor for a breast screening. & & & & & 0.62 & 0.38 \\
\hline I think that it takes too long to wait to see a doctor for a breast screening. & & & & & 0.44 & 0.24 \\
\hline I am busy and I have no time to see a doctor for a breast screening. & & & & & 0.73 & 0.55 \\
\hline I do not know how to perform a breast self-examination & & & & & 0.56 & 0.37 \\
\hline \multicolumn{7}{|l|}{ Health behavior related to breast cancer awareness (8) } \\
\hline How many days per week do you eat fried food? & & & & 0.58 & & 0.37 \\
\hline How many days per week do you eat food or dessert with coconut? & & & & 0.52 & & 0.28 \\
\hline How often do you eat beef, chicken, or duck with the fat or skin? & & & & 0.39 & & 0.22 \\
\hline How many days per week do you eat fresh vegetables? & & & & 0.35 & & 0.2 \\
\hline How many days per week do you exercise or play sports? & & & & 0.44 & & 0.29 \\
\hline $\begin{array}{l}\text { How often have youheard about the breast screening policy of the health per- } \\
\text { sonnel in your area? }\end{array}$ & & & & 0.48 & & 0.39 \\
\hline How often do you perform a clinical breast screening? & & & & 0.38 & & 0.35 \\
\hline How often do you perform a mammogram? & & & & 0.21 & & 0.1 \\
\hline
\end{tabular}

*Low loading items forced into the model 


\section{Instrument development}

An extensive literature review along with a semistructured interview of a small sample of women were conducted to identify potential items of the breast cancer awareness scale (B-CAS). Literature searches were carried out using electronic journal databases including articles written in English and published between 2005 and 2015. The Semi-structured interviews were conducted on a sample of 15 women to explore the level of Thai women's awareness and preventative behaviour of breast cancer and what barriers they feel the face. This process revealed 58 items across five domains of breast cancer awareness. Items and their domains were subsequently evaluated by twelve experts who possessed extensive experience working in the breast cancer field, behavioural sciences and psychosocial research. Some items were revised after evaluation by experts and then a pilot study was conducted to assess face validity.

In addition to nine variables related to demographic characteristics, the final version of the self-administered questionnaire included 53 items relevant to breast cancer awareness. These items were distributed among five domains of awareness: 1) knowledge of risk factors, which explores whether women know about established risk factors of breast cancer; 2) knowledge of signs and symptoms, concerned with knowledge of breast cancer symptoms and non-symptoms; 3) attitude to breast cancer prevention, consisting of items measuring attitude about breast cancer prevention; 4) barriers of breast screening, which explores personal barriers related to breast screening including emotional, practical and service delivery, and 5) health behaviour related to breast cancer awareness, which considers health behaviour related to breast cancer awareness including breast screening and healthy behaviour. To gauge the vigilance of the participants in completing the questionnaire (thinking about responses) we included some false risk factors and signs and symptoms into the questionnaire. The content summary of each domain is presented in Table 1 along with the scale used to measure items from the various domains

\section{Statistical analysis}

All data were coded in Epidata version 3.1 (Lauritsen and Bruus, 2004) and were analyzed using the R statistic language (v2.3.0; R CoreTeam, 2015) and the R library lavaan for all factor analysis (Rosseel, 2012). Exploratory factor analysis was used to explore factor structure, and to remove redundant items or those with low factor loadings. The number of factors was chosen based on principal components analysis, as well as a theoretical basis. The nature of the underlying factors was then explored using Principal Axis Factoring (Colton and Covert, 2007). After trialling several orthogonal and oblique rotations, oblimin rotation revealed a structure most consistent with the hypothesized structure of the instrument. The internal consistency reliability of the instrument overall, and the individual subscales, were evaluated using Cronbach's alpha. Acceptable reliability was set to be $\alpha>0.7$ for the scale and all subscales (Kline, 2000).

\section{Results}

A total of 219 women completed the questionnaire (Response rate: $97.4 \%$ ), and their ages ranged from 20 to 64 years old (Mean=40.74, $\mathrm{SD}=11.52$ ) with more than half of participants aged between 35 to 59 years old. Most participants $(66 \%)$ had not achieved more than a high school education, and around $70 \%$ resided in rural areas. The other demographic characteristics of the participants are shown in Table 2.

\section{Exploratory factor analysis (EFA)}

Exploratory Factor Analysis showed a five factor structures with 32 items achieving a sufficient factor loading ( $>0.2)$ and 21 items were initially excluded because of low loadings including the four 'trick question' we included. However, we decided to retain three of the 21 low loading items because their inclusion is very strongly supported by the literature. The factor loading of each item is shown in Table 3.

\section{Internal consistency}

The internal consistency reliability analysis demonstrated that the B-CAS achieved a good level of reliability with all Cronbach's alphas above 0.7. Cronbach's alpha for the overall scale (B-CAS) was $\alpha=0.858$, and the individual domains were knowledge of risk factors (0.707), knowledge of signs and symptoms (0.745), attitude to breast cancer prevention (0.827), barriers of breast screening $(0.791)$, and health behaviour related to breast cancer awareness $(0.748)$.

\section{Discussion}

To the best of our knowledge, this is the first instrument developed to assess breast cancer awareness in Thai women. Our instrument provides strong internal consistency reliability, and we demonstrate that most of the items included strongly aligned with their hypothesized constructs. The B-CAS was designed to be a self- report instrument that is easy to use, and will allow researchers and practitioners to gain a better understanding of women's awareness of breast cancer in both general survey studies and in evaluating the efficacy of breast cancer awareness interventions.

The results of our study showed that the B-CAS revealedrelevant underlying domains for the evaluation of breast cancer awareness including: knowledge of risk factors, signs and symptoms of breast cancer, attitude to breast cancer prevention, health behavior related to breast cancer awareness, and barriers to breast screening. Some domains of the B-CAS were consistent with those identified in previous research including, knowledge of risk factors, signs and symptoms and barrier to breast screening (Al-Dubai et al., 2011; Norsa'adah et al., 2012; Sathian et al., 2014; Tazhibi and Feizi, 2014; Yousuf et al., 2012). In addition to these commonly used domains, we identified domains not included in a large majority of existing instruments. In particular: attitude to breast cancer prevention, and health behavior related to breast cancer awareness, the last of which considers both healthy 
lifestyle and breast screening. We feel the addition of these domains to an instrument measuring breast cancer awareness will provide a better understanding of breast cancer awareness. For the attitude to breast cancer prevention domain, we focused on measuring individuals' attitude to practice behavior (Fazio and Zanna, 1978).

A majority of existing instruments focus primarily on breast screening behavior as an indicator of breast cancer awareness (Kanaga et al., 2011; Norlaili et al., 2013; Donnelly et al., 2014; Elobaid et al., 2014; Tazhibi and Feizi, 2014). However, several studies (Patel et al., 2003; Liu et al., 2014a; Miyawaki et al., 2014) have advocated the inclusion of health self efficacy and general health awareness as important components of breast cancer awareness.

In conducting the exploratory factor analysis, we chose the method of principal axis factoring with oblique rotation for extracting factors. The results of our analysis suggested that there were 21 items unlikely to be associated (low loadings) to breast cancer awareness and their respective domains. Normally this would be sufficient to exclude these items from future consideration. However, some of these items, especially those associated with risk factors, and signs and symptoms, are well established as associated with breast cancer (American Cancer Society, 2015; Nelson et al., 2012).We decided to force three of these 21 items into the model, and see if they should still be excluded in a subsequent confirmatory factor analysis. In particular, family history for the risk factor domain ,and the discharge or bleeding from your nipple, and a lump or thickening in your breast items for the signs and symptoms subscale were forced into the model.

Our study does have some limitations. First, we considered women from a single province in southern Thailand. The representativeness of this sample for all Thai women is not known. Second, at this stage of the validation process, B-CAS has not yet undergone a construct or criterion-based validation. As yet, there is no evidence that this instrument could either discriminate between women with low or high breast cancer awareness, or be used to evaluate the efficacy of a program to raise awareness (predictive validity).

This study also had some major strengths. First, we undertook a thorough literature review and complied a comprehensive pool of items which were subsequently evaluated by a panel of experts. Second, our instrument was developed for the general women population. In contrast, Breast-CAM (Linsell et al., 2010), currently the most widely used measure of breast cancer awareness, has only been validated on older women (67-73 years). Third, a majority of breast cancer awareness instrument validations have had major methodological limitations, or fallen well short of full validation. For instance, few have conducted factor analysis to either empirically justify, or construct validate their reported domains. Our study included an appropriate exploratory factor analysis (principal axis factoring) to identify the domains underlying the B-CAS, and we plan to conduct Confirmatory Factor Analysis and criterion-based validation in a future study. In contrast, the most widely use instrument for evaluating breast cancer awareness in women, Breast CAM (Linsell et al., 2010), was structured in such a way as to make full psychometric validation difficult. Indeed, this was one of the main motivating factors in our development of the B-CAS.

In conclusion, the B-CAS showed good psychometric properties in terms of content validity and internal consistency reliability suggesting it will have utility in assessing breast cancer awareness in Thai women. It is a self-report instrument, easy to use, quick and inexpensive to apply in both surveys of breast cancer awareness and, in future, may be used to gauge the efficiency of awareness interventions.

\section{Acknowledgements}

The authors would like to thank all participating women in this study, all research assistants for data collection in Suratthani province, and the graduate school of Khon Kaen University for financial support.

\section{References}

Akinyemiju TF (2012). Socio-economic and health access determinants of breast and cervical cancer screening in low-income countries: analysis of the World Health Survey. PloS one, 7, 48834.

Al-Dubai SA, Qureshi AM, Saif-Ali R, et al (2011). Awareness and knowledge of breast cancer and mammography among a group of Malaysian women in Shah Alam. Asian Pac J Cancer Prev, 12, 2531-8.

American Cancer Society. (2015). Signs and symptoms of breast cancer. Retrieved September 1, 2015, from http:// www.cancer.org/cancer/breastcancer/detailedguide/breastcancer-signs-symptoms

Comrey AL, Lee, HB (1992). A First Course in Factor Analysis. Hillsdale, NJ: Erlbaum.

Donnelly TT, Al Khater AH, Al-Bader SB, et al (2013). Beliefs and attitudes about breast cancer and screening practices among Arab women living in Qatar: a cross-sectional study. BMC Women's Health, 13, 49.

Donnelly TT, Khater A H, Al-Bader SB, et al (2014). Factors that influence awareness of breast cancer screening among Arab women in Qatar: results from a cross sectional survey. Asian Pac J Cancer Prev, 15, 10157-64.

Elobaid YE, Aw TC, Grivna M, Nagelkerke N (2014). Breast cancer screening awareness, knowledge, and practice among arab women in the United Arab Emirates: a cross-sectional survey. PloS one, 9, 105783.

Fazio Russell H, Zanna Mark P (1978). Attitudinal qualities relating to the strength of the attitude-behavior relationship. 14, 398-408.

Ferlay J, Soerjomataram I, Ervik M, et al (2012). GLOBOCAN 2012 v1.0, cancer incidence and mortality worldwide: iarc cancerbase No. 11 [Internet]. lyon, france: international agency for research on cancer; 2013.

Gurdal SO, Saracoglu GV, Oran ES, Yankol Y, Soybir GR (2012). The effects of educational level on breast cancer awareness: a cross-sectional study in Turkey. Asian Pac J Cancer Prev, 13, 295-300.

Jones SC, Gregory P, Nehill C, et al (2010). Australian women's awareness of breast cancer symptoms and responses to potential symptoms. Cancer Causes Control, 21, 945-958.

Kanaga KC, Nithiya J, Shatirah MF (2011). Awareness of breast cancer and screening procedures among Malaysian women. Asian Pac J Cancer Prev, 12, 1965-7.

Khokhar,A. (2009). Level of awareness regarding breast cancer 
Nitchamon Rakkapao et al

and its screening amongst Indian teachers. Asian Pac J Cancer Prev, 10, 247-250.

Khuhaprema, T, Attasara, P, Sriplung, H, Wiangnon, S, and Sangrajrang, S (2013). Cancer in Thailand. Volume VII, 2007-2009: National Cancer Institude, Bangkok.

Khuhaprema, T, Attasara, P, Sriplung, H, et al (2012). Cancer in Thailand. Volume VI, 2004-2006. National Cancer Institude, Bangkok.

Khuhaprema T, Srivatanakul P, Attasara P, et al (2010). Cancer in Thailand. Volume V, 2001-2003. National Cancer Institude, Bangkok.

Kline P (2000). The handbook of psychological testing ( $\left.2^{\text {nd }} e d.\right)$. London: Routledge.

Kwok C, Fethney J, White K (2012). Breast cancer screening practices among chinese-australian women. European $J$ Oncol Nurs, 16, 247-52.

Linsell L, Forbes LJ, Burgess C, et al (2010). Validation of a measurement tool to assess awareness of breast cancer. European J Cancer, 46, 1374-1381.

Liu LY, Wang F, Yu LX, et al (2014s). Breast cancer awareness among women in Eastern China: a cross-sectional study. BMC Public Health, 14, 1004.

Long N, Moore MA, Chen, W, et al (2010). Cancer epidemiology and control in north-East Asia - past, present and future. Asian Pac J Cancer Prev, 11, 107-48.

Miyawaki R, Shibata A, Ishii K, Oka K (2014). Awareness and correlates of the role of physical activity in breast cancer prevention among Japanese women: results from an internetbased cross-sectional survey. BMC Women's Health, 14, 80.

Moore MA, Ariyaratne Y, Badar F, et al (2010). Cancer epidemiology in South Asia - past, present and future. Asian Pac J Cancer Prev, 11, 49-66.

Moore MA, Attasara P, Khuhaprema T, et al (2010). Cancer epidemiology in mainland South-East Asia - past, present and future. Asian Pac J Cancer Prev, 11, 67-80.

Moore MA, Manan AA, Chow KY, et al (2010). Cancer epidemiology and control in peninsular and island SouthEast Asia - past, present and future. Asian Pac J Cancer Prev, 11, 81-98.

Nelson Heidi D, Zakher Bernadette, Cantor Amy, et al (2012). Risk factors for breast cancer for women aged 40 to 49 years: a systematic review and meta-analysis. Ann Intern Med, 156, 635-48.

Norlaili AA, Fatihah MA, Daliana NF, Maznah D (2013). Breast cancer awareness of rural women in Malaysia: is it the same as in the cities? Asian Pac J Cancer Prev, 14, 7161-4.

Norsa'adah B, Rahmah MA, Rampal KG, Knight A (2012). Understanding barriers to Malaysian women with breast cancer seeking help. Asian Pac J Cancer Prev, 13, 3723-30.

Patel AV, Callel EE, Bernstein L, Wu AH, Thun MJ (2003). Recreational physical activity and risk of postmenopausal breast cancer in a large cohort of US women. Cancer Causes Control, 14, 519-29.

Radi SM (2013). Breast Cancer awareness among Saudi females in Jeddah. Asian Pac J Cancer Prev, 14, 4307-12.

Ranasinghe HM, Ranasinghe N, Rodrigo C, Seneviratne Rde A, Rajapakse S (2013). Awareness of breast cancer among adolescent girls in Colombo, Sri Lanka: a school based study. BMC Public Health, 13, 1209.

RCoreTeam (2015). R: A language and environment for statistical computing. R Foundation for Statistical Computing, Vienna, Austria.

Rosseel, Yves (2012). lavaan: An R Package for Structural Equation Modeling. J Statistical Software, 48, 1-36.

Sathian B, Nagaraja SB, Banerjee I, et al (2014). Awareness of breast cancer warning signs and screening methods among female residents of Pokhara valley, Nepal. Asian Pac J
Cancer Prev, 15, 4723-6.

Tazhibi M, Feizi A (2014). Awareness levels about breast cancer risk factors, early warning signs, and screening and therapeutic approaches among Iranian adult women: a large population based study using latent class analysis. BioMed Res Int , 2014, 306352.

National Cancer Institute of Thailand (2010). Hospital-based cancer registry 2010 Retrieved March 22, 2015, from http:// www.nci.go.th

National Cancer Institute of Thailand. (2011). Hospital-based cancer registry 2011 Retrieved March 22, 2015, from http:// www.nci.go.th

National Cancer Institute of Thailand. (2012). Hospital-based cancer registry 2012 Retrieved March 22, 2015, from http:// www.nci.go.th

Tripathi N, Kadam YR, Dhobale RV, Gore AD (2014). Barriers for early detection of cancer amongst Indian rural women. South Asian J Cancer, 3, 122-127.

Unger-Saldana, K. (2014). Challenges to the early diagnosis and treatment of breast cancer in developing countries. World $J$ Clin Oncol, 5, 465-77.

Wu TY, Chung S, Yeh MC, et al (2012). Understanding breast cancer screening practices in Taiwan: a country with universal health care. Asian Pac J Cancer Prev, 13, 4289-94.

Yoo BN, Choi KS, Jung KW, Jun JK (2012). Awareness and practice of breast self-examination among Korean women: results from a nationwide survey. Asian Pac J Cancer Prev, 13, 123-5.

Youlden DR, Cramb SM, Yip CH, Baade PD (2014). Incidence and mortality of female breast cancer in the Asia-Pacific region. Cancer Biol Med, 11, 101-15.

Yousuf SA, Al Amoudi SM, Nicolas W, Banjar HE, Salem SM (2012). Do Saudi nurses in primary health care centres have breast cancer knowledge to promote breast cancer awareness? Asian Pac J Cancer Prev, 13, 4459-64. 